Graphical Abstract

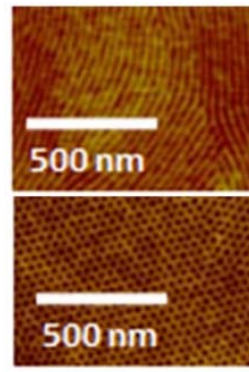

Orientation Control

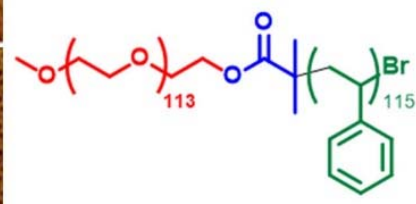

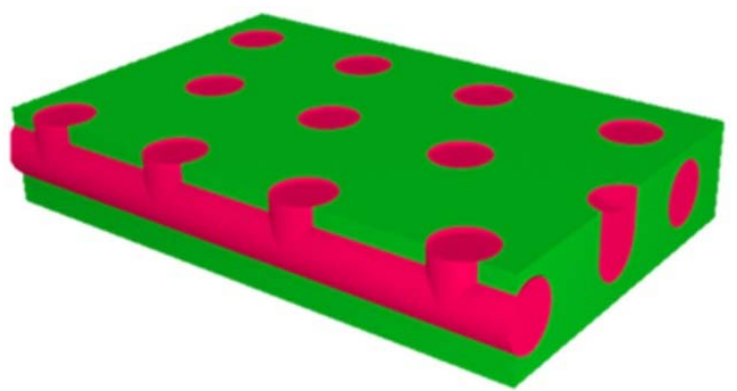




\title{
Improving Humidity-Controlled Solvent Annealing Processes for Block Copolymer Poly(Ethylene Oxide)-b-Polystyrene
}

\author{
Jeffery Hayat, ${ }^{\dagger}$ Indranil Mitra, ${ }^{\ddagger}$ Yali Qiao, ${ }^{\dagger}$ Gila E. Stein, ${ }^{\ddagger *}$ Chuanbing Tang ${ }^{\dagger *}$ \\ †Department of Chemistry \& Biochemistry, University of South Carolina, Columbia, South \\ Carolina 29208, United States. \\ ${ }^{\ddagger}$ Department of Chemical \& Biomolecular Engineering, University of Houston, Houston, Texas \\ 77204, United States \\ * Corresponding Author E-mail: tang4@mailbox.sc.edu; gestein@uh.edu
}

\begin{abstract}
This paper addresses two challenges in humidity-controlled solvent annealing of poly(ethylene oxide)- $b$-polystyrene thin films: (1) reduction in annealing time by nearly an order of magnitude for toluene under high humidity, which is achieved by decreasing the annealing chamber volume; (2) utilization of two industry-benign solvents, methyl ethyl ketone (MEK) and propylene glycol monomethyl ether acetate (PGMEA), to achieve ordered surface patterns under high humidity. When toluene is employed for annealing, the rate of block copolymer ordering is controlled by the time required to saturate the vapor phase, which depends on the chamber size in this study. The kinetics with MEK and PGMEA are more complex: While saturation time plays a role, these solvents reduce the incompatibility between PS and PEO, so longer annealing times are required to achieve good lateral order. We also present evidence that lateral ordering is faster than lattice swelling in the small chamber, so large grains are achieved without inflating the domain size and periodicity.
\end{abstract}

\section{Introduction}

Block copolymers are comprised of chemically distinct segments that are covalently bonded together. The thermodynamic immiscibility of these polymers drives the formation of microphase separated domains with tunable size, shape, and periodicity. The morphologies of block copolymers are controlled by their molecular characteristics.[1-5] There are three principal 
experimental parameters that dictate how a diblock copolymer microphase separates: FloryHuggins interaction parameter $(\chi)$, degree of polymerization $(N$, proportional to molecular weight), and volume fraction of one of the blocks $(f)$.[6] The product $\chi N$ controls the strength of segregation. The size and periodicity of nanostructures is tuned through changes in $N$, while phases are largely controlled by $f$.

Block copolymer thin films are used for nanolithographic masks,[7-12] templates for inorganic nano-objects,[8, 13-15] magnetic storage media,[16] and devices.[17, 18] These applications require good lateral ordering of the domains, and for anisotropic morphologies (lamellae and cylinders), the orientation of domains with respect to the interfaces must also be controlled. Lamellae and cylinders can align either parallel or perpendicular to a substrate depending on interfacial energetics and external structure-directing potentials. Popular examples of external potentials include electric fields,[19-22] chemically patterned substrates (chemoepitaxy),[23, 24] and topographically patterned substrates (graphoepitaxy).[25, 26]

This manuscript focuses on two challenges in the high-humidity solvent annealing process of poly(ethylene oxide- $b$-styrene) (PEO- $b$-PS) diblock copolymer thin films: reduction of annealing time and implementation of two industry-benign solvents. Solvent annealing can induce domain ordering by plasticizing the copolymer to allow diffusion, modifying the effective $\chi$ parameter, and tuning energetics at the air interface to favor lateral ordering.[27-35] In addition to controlling solvent vapor pressure, humidity controls can be used to tailor surface interactions in copolymers with a hydrophilic block (such as PEO) and facilitate lateral ordering.[36-43] These procedures are well-documented with PEO- $b$-PS copolymers that form PEO cylinders or spheres in a PS matrix, and can induce long-range lateral ordering with grain sizes on the order of micrometers.[44-47]

High-humidity solvent annealing requires control over critical parameters such as solvent type, relative humidity (RH\%), and annealing time. An appropriate solvent will solubilize both copolymer blocks. While many organic solvents meet this criterion for PEO- $b$-PS, the most commonly-employed reagents are carcinogenic or suspected carcinogenic, so they are not desirable for industrial processes. RH controls the lateral ordering of PEO domains at the film surface. For example, earlier work on cylindrical PEO- $b$-PS demonstrated that high RH (>90\%) promotes perpendicular orientation at the surface whereas low $\mathrm{RH}(<80 \%)$ leads to parallel 
layers through the film thickness.[46] Furthermore, solvent vapor pressure and the solubility between the block copolymer and solvent partly determine the time needed for annealing.

Scheme 1: A humidity-controlled solvent annealing process for block copolymer PEO- $b$-PS in thin films.
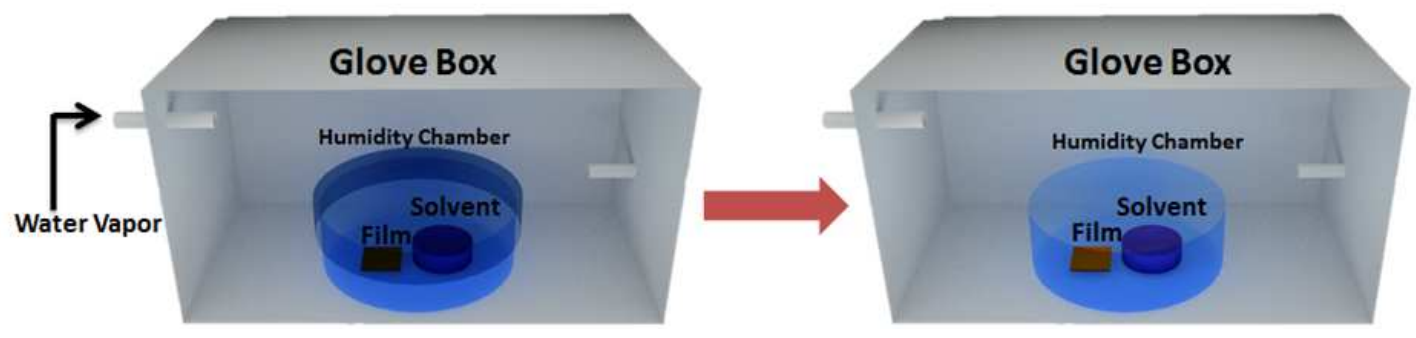

Scheme 1 illustrates the solvent annealing process that is employed in this work. A thin film of PEO- $b$-PS is placed inside a small chamber that includes a solvent reservoir, and the chamber was placed in a humid glove box. The small chamber consists of an upside-down petri dish over a petri dish containing the solvent reservoir and film. The upside-down petri dish acts a cover in the system. The small chamber was sealed by placing a heavy metal on top of the cover. The chamber becomes saturated with solvent vapor, which causes the film to form a swollen and homogenous polymer layer on the substrate. The top of the small chamber (upside-down petri dish) was then opened and removed from inside the humid glove box. The exposure of the thin film to the large reservoir of the humid environment (>90\%) would initiate a "de-swelling" process where the solvent evaporates from the film surface and leads to the formation of a concentration gradient in the film. Simultaneously, water vapor (humid environment) is preferentially solubilized by hydrophilic PEO segments and induces ordering of PEO domains on the surface. As solvent continues to evaporate, the ordering at the surface can propagate into the film.[17, 37, 38, 45, 48] It is important to note that de-swelling of the thin film is not affected by the volume of the small chamber since the de-swelling occurs only after the top of the chamber is removed.

There are two underlying practical challenges for this high-humidity solvent annealing process. First, annealing time needs to be significantly reduced. The typical timescale to achieve long-range lateral order in PEO- $b$-PS copolymers is hours to days, so it is not appropriate for high throughput production. Second, we demonstrate that long-range lateral order in PEO- $b$-PS thin films is achieved in minutes with humid toluene vapor by simply decreasing the annealing 
chamber volume. We also report the use of industry-benign solvents, such as methyl ethyl ketone (MEK) and propylene glycol monomethyl ether acetate (PGMEA), to achieve ordered surface patterns. These simple changes to high-humidity solvent annealing protocols are easily implemented in any laboratory environment.

\section{Experimental Section}

Materials. Tetrahydrofuran (THF) and dimethylformamide (DMF) were dried over molecular sieves and distilled before use. Styrene was passed through a basic alumina column before use. $N, N, N$ ',$N$ ",$N$ "-pentamethyldiethylenetriamine (PMDETA, Aldrich) and triethylamine $\left(\mathrm{Et}_{3} \mathrm{~N}\right.$, 99\%, Aldrich) were distilled before use. $\mathrm{Cu}(\mathrm{I}) \mathrm{Br}$ (99.999\% Aldrich) and 2-bromoisobutyryl bromide (Aldrich) used as received. Toluene (99\%), methyl ethyl ketone (MEK, 99.0\%), and propylene glycol monomethyl ether acetate (PGMEA, 99.5\%) were purchased from Sigma Aldrich and used as received. All other reagents and solvents were purchased from Sigma Aldrich or Alfa Aesar and used as received.

Synthesis of PEO-b-PS. As shown in Scheme S1, the preparation of block copolymer poly(ethylene oxide)-block-polystyrene (PEO-b-PS) followed procedures reported earlier.[38, 40, 49] This block copolymer has a number-average molecular weight of $18,000 \mathrm{Da}$ with the PEO fraction at $28 \mathrm{wt} \%$ and a dispersity of 1.10 .

Characterization. Gel permeation chromatography (GPC) was performed at $50{ }^{\circ} \mathrm{C}$ on a Varian system equipped with a Varian 356-LC refractive index detector and a Prostar 210 pump. The columns were STYRAGEL HR1, HR2 $(300 \times 7.5 \mathrm{~mm})$ from Agilent. HPLC grade DMF was used as eluent flow rate of $1.0 \mathrm{~mL} / \mathrm{min}$. Polystyrene standards were used for calibration.

Preparation of Thin Films. A block copolymer (1.5 wt $\%$ ) toluene solution was spin coated (3000 RPM, $60 \mathrm{~s}$ ) onto oxidized silicon substrates (100 nm thick thermal oxide). The thin films were annealed in a glove box with controlled humidity as shown in Scheme 1. Three different solvents were used for solvent annealing: toluene, MEK, and PGMEA. Annealing time was varied for each solvent. All films were saturated with solvent vapor in a chamber before exposure in the humid glove box. Grain sizes were determined by measuring areas of complete 
grains from at least five different micrographs and calculating an average of selected areas. Film thicknesses were measured with a J.A. Woollam spectroscopic ellipsometer with an incident angle of $70^{\circ}$. Ellipsometry data $(\Delta, \Psi)$ were modeling using the Cauchy dispersion relation to describe the refractive index of the polymer film, i.e., $\mathrm{n}(\lambda)=A+B / \lambda^{2}$, where $A, B$, and polymer film thickness were adjustable parameters for regression analysis (all positive values). All film thicknesses were in the range of 55 to $65 \mathrm{~nm}$.

Atomic Force Microscopy. Atomic force microscopy (AFM) was performed using a Multimode Nanoscope V system (Bruker, Santa Barbara, CA). Tapping mode AFM was used to map the topography by tapping the surface using an oscillating tip. The measurements were performed using commercial Si cantilevers with a nominal spring constant and resonance frequency at 20$80 \mathrm{~N} \mathrm{~m}^{-1}$ and 230-410 kHz, respectively (TESP, Bruker AFM Probes, Santa Barbara, CA). The spacing between close-packed rows of dots or adjacent parallel cylinders was calculated from the power spectral density using the Bruker software. The sizes of ordered "grains" were calculated from AFM micrographs using ImageJ software: Grain boundaries were traced using the polygon option. We calculate the area of each polygon, and then define a circle of equal area to calculate the grain "diameter". (Grains that extend outside the range of the image were excluded from the analysis.) The image sizes used for this analysis ranged from $2 \mu \mathrm{m}$ at short times up to $4 \mu \mathrm{m}$ at longer times. The standard deviation is based on the average from 2-3 images per sample.

Grazing-Incidence Small Angle X-ray Scattering (GISAXS). GISAXS experiments were performed at beam line 8-ID-E at the Advanced Photon Source of Argonne National Laboratory. Samples were placed in a low vacuum chamber and illuminated with $7.35 \mathrm{keV}(\lambda=0.168 \mathrm{~nm})$ radiation at incident angles in the range of $0.1-0.24^{\circ}$ (critical angle of the polymer is approximately $\left.0.16^{\circ}\right)$. The off-specular scattering was recorded with a Pilatus $1 \mathrm{MF}$ pixel array detector (pixel size $=172 \mu \mathrm{m}$ ) positioned $2175 \mathrm{~mm}$ away from the sample. Slit sizes were $50 \mu \mathrm{m}$ (vertical) and $100 \mu \mathrm{m}$ (horizontal). Acquisition times were on the order of $10 \mathrm{sec}$ for each incident angle. Each data set is stored as a $981 \times 1043$ 32-bit tiff image with 20-bit dynamic range. Note that $\alpha_{\mathrm{i}}, \alpha_{\mathrm{f}}$, and $\alpha_{\mathrm{c}}$ denote the incident angle, exit angle, and critical angle of the polymer, respectively. 


\section{Results and Discussion}

A linear diblock copolymer was synthesized using mono-functional poly(ethylene oxide) (PEO), as shown in Scheme S1.[49] Mono-hydroxyl terminated PEO (1) with a numberaveraged molecular weight $5000 \mathrm{Da}$ was converted into an atom transfer radical polymerization (ATRP) macroinitiator (2) by reacting the terminal hydroxide group with 2-bromoisobutyrl bromide in the presence of triethylamine. Block copolymer PEO- $b$-PS (3) was synthesized by chain extension of the macroinitiator (2) with styrene using $\mathrm{Cu}(\mathrm{I}) \mathrm{Br}$ and PMDETA as the catalyst system at $90{ }^{\circ} \mathrm{C}$. The molecular weight of polystyrene was monitored by proton NMR (Figure S1). The monomer conversion was obtained by calculating the decrease in styrene monomer signals at 5.74 and $5.22 \mathrm{ppm}$ as compared to the PEO backbone protons at 3.47-3.77 ppm. The final block copolymer has a molecular weight 18,000 Da with a PEO fraction of 28.0 wt $\%$ and dispersity $(\nexists)$ of 1.10 . It has been well demonstrated that PEO- $b$-PS with a PEO (5000 Da) block in the range of 20-30 wt\% can produce cylindrical morphologies both in bulk and thin films under humidity-controlled solvent annealing.[36-39, 41-45]

Films of PEO-b-PS with thicknesses of $\sim 60 \mathrm{~nm}$ were spin-cast on silicon/silicon oxide substrates from $1.5 \mathrm{wt} \%$ toluene solutions. The films were then subjected to the high-humidity annealing protocol introduced in Scheme 1. The chamber sizes were $1236 \mathrm{~cm}^{3}$ ("large") and 64 $\mathrm{cm}^{3}$ ("small") (Scheme S2). The solvent reservoir inside the chamber has a volume of $15.7 \mathrm{~cm}^{3}$. Three solvents were compared: toluene, MEK and PGMEA. The efficacy of toluene in highhumidity solvent annealing processes has been established by other studies,[36-39, 41-45] and thus these outcomes serve as a reference for the current work with more benign MEK and PGMEA. All films were solvent annealed for times ranging from 0.5 hours to 20 hours, and then "de-swelled" for a period of time in the humid glove box.

Hansen solubility parameters for PS, PEO, and each solvent are summarized in Table 1, and were used to predict the Flory-Huggins $\chi$-parameter for each polymer/solvent pair:[50]

$$
\chi=\frac{v_{s} A_{12}}{R T}
$$

where $v_{s}$ is the solvent molar volume, and the exchange-energy density of two components is 


$$
A_{12}=\left(\delta_{d}^{1}-\delta_{d}^{2}\right)^{2}+0.25\left(\delta_{p}^{1}-\delta_{p}^{2}\right)^{2}+0.25\left(\delta_{h}^{1}-\delta_{h}^{2}\right)^{2}
$$

Predicted $\chi$-parameters are summarized in Table 2. Toluene is selective to the PS domains, while all other solvents are selective to PEO. Note that the values for PS/solvent pairs are consistent with other predictions and experimental measurements.[50]

Table 1: Hansen solubility parameters.

\begin{tabular}{|c|c|c|c|}
\hline Material & $\delta_{\mathrm{d}}\left(\mathrm{MPa}^{1 / 2}\right)$ & $\delta_{\mathrm{p}}\left(\mathrm{MPa}^{1 / 2}\right)$ & $\delta_{\mathrm{h}}\left(\mathrm{MPa}^{1 / 2}\right)$ \\
\hline PS[51] & 18.6 & 0.2 & 0 \\
\hline PEO[52] & 16.3 & 6.1 & 9.4 \\
\hline Toluene[50] & 18.0 & 1.4 & 2.0 \\
\hline MEK[50] & 16.0 & 9.0 & 5.1 \\
\hline PGMEA[53] & 16.1 & 6.1 & 6.6 \\
\hline Water[52] & 15.5 & 16.0 & 42.4 \\
\hline
\end{tabular}

Table 2: Estimated $\chi$-parameters at $298 \mathrm{~K}$ for each polymer/solvent system.

\begin{tabular}{|c|c|c|}
\hline & PS & PEO \\
\hline Toluene & 0.26 & 0.94 \\
\hline MEK & 0.43 & 0.26 \\
\hline PGMEA & 0.41 & 0.11 \\
\hline Water & 2.84 & 2.15 \\
\hline
\end{tabular}

The vapor pressures of toluene, MEK, and PGMEA are summarized in Table 3 for $25^{\circ} \mathrm{C}$. The vapor pressure $\left(P^{v a p}\right)$ will control the concentration of solvent vapor in the chamber, while both $P^{v a p}$ and $\chi$ will determine the solvent fraction in the film $\left(\varphi^{s}\right)$. The equilibrium solvent fraction is estimated with Flory-Huggins theory: The chemical potential of solvent in the vapor phase and the film must be equal at equilibrium, leading to Equation 3: 


$$
\ln \left(P^{v a p} / P^{0}\right)=\chi\left(1-\varphi^{s}\right)+\ln \left(\varphi^{s}\right)+(1-1 / N)\left(1-\varphi^{s}\right)
$$

where $P^{0}$ is a reference state of $1.01 \mathrm{bar}$ (normal boiling). Results are reported in Table 3. Vapor pressure has the strongest impact on solvent concentration in the film, and polymer-solvent compatibility plays a secondary role. The predicted concentration for the toluene/PS system is consistent with other literature studies that directly measure solvent uptake.[54]

Table 3: Solvent vapor pressure at $25^{\circ} \mathrm{C}$ and equilibrium concentration of solvent in the PS and PEO domains (volume fractions $\varphi^{s}$ ).

\begin{tabular}{|l|c|c|c|}
\hline Solvent & $\boldsymbol{P}^{\text {va }}$ at $\mathbf{2 5}^{\mathbf{0}} \mathbf{C}(\mathbf{b a r})$ & $\boldsymbol{\varphi}^{\boldsymbol{s}}(\mathbf{P S})$ & $\boldsymbol{\varphi}^{\boldsymbol{s}}($ PEO) \\
\hline Toluene & 0.038 & 0.01 & 0.006 \\
\hline MEK & 0.127 & 0.03 & 0.04 \\
\hline PGMEA & 0.007 & 0.002 & 0.002 \\
\hline
\end{tabular}

The first solvent employed was toluene. All films annealed under toluene were allowed to de-swell for 15 minutes. It typically takes more than 10 hours to achieve highly ordered PEO- $b$ PS thin films in a large chamber (volume of $1236 \mathrm{~cm}^{3}$ ). When the annealing time was less than 1 hour, the films (1a, 1b and 1c in Table 4 and Figure S2) were either disordered or had extremely small grains of hexagonally-packed arrays. Only annealing times in excess of 6 hours could result in ordered thin films (1e and 1f in Table 4 and Figure S2). However, when the chamber volume was decreased to $64 \mathrm{~cm}^{3}$, laterally ordered films were obtained in a matter of minutes, and further annealing up to 3 hours produced single grains spanning more than $2.5 \mu \mathrm{m}^{2}$. Figure 1 shows AFM height images that illustrate the evolution of order achieved with a small chamber volume (samples 2a-d in Table 4). After 0.25 hour of annealing, the PEO domains are hexagonally ordered at the air surface. Some areas of the film exhibit long-range order, while other regions exhibit liquid-like order. Such extremity indicates that the system is highly unbalanced. Nevertheless, the distance between close-packed rows is $d=23 \mathrm{~nm}$. After $0.5 \mathrm{hr}$, the domains at the air interface are laterally-ordered into large hexagonal grains that span nearly 1.5 $\mu \mathrm{m} \times 1.5 \mu \mathrm{m}$ with $d=25 \mathrm{~nm}$ (Figure 1b). This is a significant observation as this level of ordering is sufficient for many applications.[55-57] A $1 \mathrm{hr}$ annealing increased the average grain size to $1.9 \mu \mathrm{m} \times 1.9 \mu \mathrm{m}$ with $d=26 \mathrm{~nm}$. When the annealing time was extended to 3 hours, a 
highly ordered thin film with an average grain size of $2.8 \mu \mathrm{m} \times 2.8 \mu \mathrm{m}$ and $d=26 \mathrm{~nm}$ was obtained. The grain size was similar to or even better than those films annealed for more than 16 hours in the large chamber (sample 1f in Table 4 and Figure S2). Figure 2 directly compares the effect of chamber size on the ordering of block copolymers in thin films as a function of annealing time using toluene as the solvent. We omit the data for Figure 1A, as the sample exhibited coexistence between highly ordered and highly disordered grains.

Another point of interest relates to swelling of the lattice during the annealing process (captured by changes in $d$ ). The swelling is a strong function of annealing time and a weak function of chamber size, without any clear coupling to the extent of lateral order. This is a significant observation for lithography, as these data demonstrate that the smaller chamber not only reduces the annealing time, but results in patterns with smaller pitch (Figure S3).

Table 4: Annealing conditions and results for block copolymer PEO- $b$-PS thin films in large and small chambers with toluene as annealing solvent. "Disordered" grain size consists of both parallel and perpendicular domains on the surface with no degree of ordering to determine average grain size. " $=$ " means cylinders parallel to the surface, " $\perp$ " means hexagonally-packed domains on the surface. Average grain size depicts the size of continuous ordered grains in the AFM micrographs only if perpendicular or parallel domains were present. De-swelling time $=15$ minutes.

\begin{tabular}{|c|c|c|c|c|c|}
\hline Sample & $\begin{array}{c}\text { Chamber } \\
\text { Size } \\
\text { (Volume) }\end{array}$ & $\begin{array}{c}\text { Annealing } \\
\text { Time }\end{array}$ & $\begin{array}{c}\text { Relative } \\
\text { Humidity } \\
(+/-3 \%)\end{array}$ & d (nm) & Average Grain Size \\
\hline $1 \mathrm{a}$ & $1236 \mathrm{~cm}^{3}$ & 0.25 hour & $88 \%$ & 25 & Disordered \\
\hline $1 b$ & $1236 \mathrm{~cm}^{3}$ & 0.5 hour & $89 \%$ & 25 & “د”, $0.22 \mu \mathrm{m} \times 0.22 \mu \mathrm{m}$ \\
\hline $1 \mathrm{c}$ & $1236 \mathrm{~cm}^{3}$ & 1 hour & $88 \%$ & 26 & "上", $0.49 \mu \mathrm{m} \times 0.49 \mu \mathrm{m}$ \\
\hline $1 d$ & $1236 \mathrm{~cm}^{3}$ & 3 hours & $90 \%$ & 27 & "工”, $1.2 \mu \mathrm{m} \times 1.2 \mu \mathrm{m}$ \\
\hline $1 \mathrm{e}$ & $1236 \mathrm{~cm}^{3}$ & 6 hours & $90 \%$ & 31 & "上", $2 \mu \mathrm{m} \times 2 \mu \mathrm{m}$ \\
\hline 1f & $1236 \mathrm{~cm}^{3}$ & 16 hours & $90 \%$ & 33 & 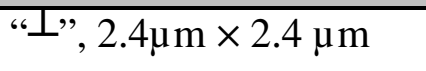 \\
\hline $2 \mathrm{a}$ & $64 \mathrm{~cm}^{3}$ & 0.25 hour & $88 \%$ & 23 & Ordered/Disordered \\
\hline $2 b$ & $64 \mathrm{~cm}^{3}$ & 0.5 hour & $89 \%$ & 25 & "工", $1.5 \mu \mathrm{m} \times 1.5 \mu \mathrm{m}$ \\
\hline $2 c$ & $64 \mathrm{~cm}^{3}$ & 1 hour & $88 \%$ & 26 & "上", $1.9 \mu \mathrm{m} \times 1.9 \mu \mathrm{m}$ \\
\hline $2 d$ & $64 \mathrm{~cm}^{3}$ & 3 hours & $90 \%$ & 26 & “上”, $2.8 \mu \mathrm{m} \times 2.8 \mu \mathrm{m}$ \\
\hline
\end{tabular}



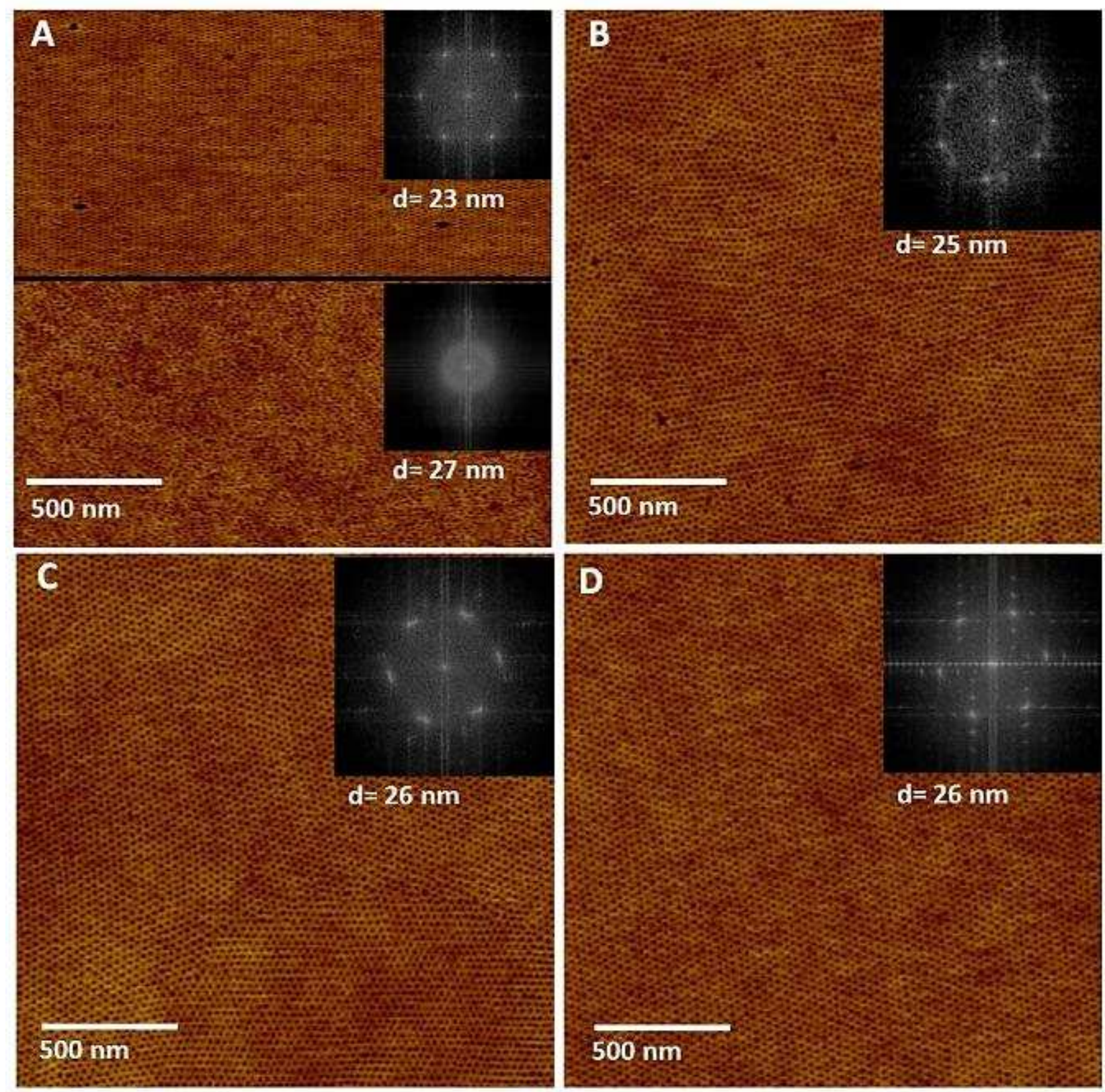

Figure 1: AFM height images of thin films of block copolymer PEO- $b$-PS processed by high humidity solvent annealing in toluene under varied annealing time in a small chamber: $(\mathrm{A}=\mathbf{2 a}$, $0.25 \mathrm{hr} ; \mathrm{B}=\mathbf{2 b}, 0.5 \mathrm{hr} ; \mathrm{C}=\mathbf{2 c}, 1 \mathrm{hr} ; \mathrm{D}=\mathbf{2 d}, 3 \mathrm{hr}$ ). 


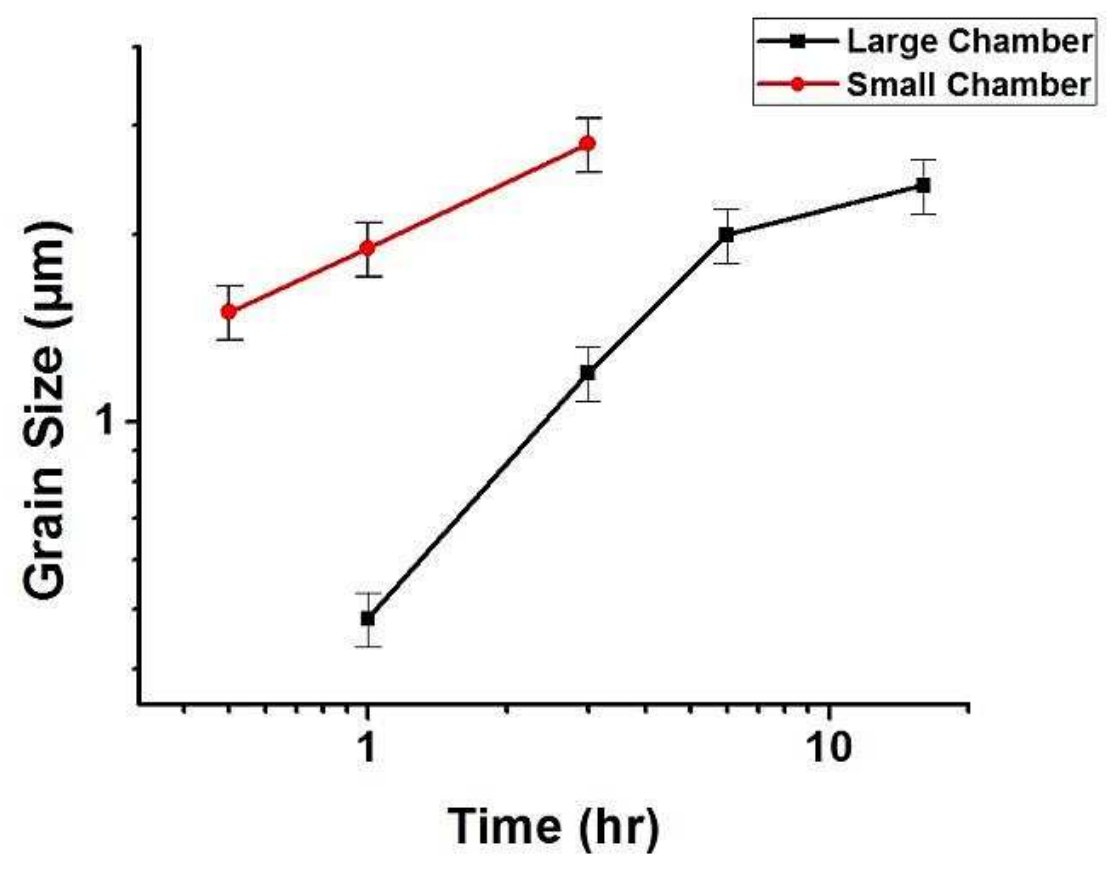

Figure 2: Lateral grain size in PEO-b-PS thin films as a function of time. High-humidity toluene solvent annealing in large and small chambers (Small Chamber 2b-2d and Large Chamber 1c1f.).

The smaller chamber clearly reduces the annealing time that is needed to achieve good lateral order, so we now discuss the cause of the enhanced ordering kinetics. We model the transient concentration profiles in the chamber with Fick's second law,

$$
\frac{\partial c_{s}}{\partial t}=D_{s a} \frac{\partial^{2} c_{s}}{\partial z^{2}}
$$

where $c_{s}[t, z]$ is the concentration of solvent in the vapor phase, $D_{s a}$ is the diffusivity of solvent in the vapor phase, and $z$ is the linear distance from the source. A one-dimensional model is selected for simplicity (and visualization.). It is important to note that the calculations based on a 1D model do not account for chamber shapes. Herein, we assume that evaporation proceeds under isothermal and isobaric conditions.

The chamber initially has no solvent vapor, so the first boundary condition we apply is:

$$
c_{s}[0, z]=0
$$


At the surface of the liquid $(z=0)$ we assume the partial pressure of solvent in the vapor phase can be modeled as an ideal gas, i.e., $p_{\mathrm{s}}[\mathrm{t}, 0]=P^{v a p}$. This leads to the second boundary condition:

$$
c_{S}[t, 0]=\frac{P^{v a p}}{R T}
$$

where $R=83.14 \mathrm{bar} \mathrm{cm}^{3} \mathrm{~mol}^{-1} \mathrm{~K}^{-1}$ and $T=298 \mathrm{~K}$ is the temperature in the glove box. The third boundary condition pertains to the wall of the chamber (at $z=L$ ). We start with the assumption that the boundary is impermeable:

$$
\left.\frac{\partial c_{s}}{\partial z}\right|_{z=L}=0
$$

The vapor pressure of toluene is 0.038 bar at $298 \mathrm{~K}$, so $c_{s}[t, 0]=1.5 \times 10^{-6} \mathrm{~mol} / \mathrm{cm}^{3}$. The diffusivity of toluene in air at $298 \mathrm{~K}$ can be approximated from empirical correlations adapted from classical kinetic theory, such as equation 1 in Wilke and Lee et al,[58] and is approximately $0.2 \mathrm{~cm}^{2} / \mathrm{sec}$. We set the chamber "length" $L$ based on the sizes of each chamber: The small chamber has a diameter of $9 \mathrm{~cm}$ and height $1 \mathrm{~cm}$, while the large chamber has a diameter of 15 $\mathrm{cm}$ and a height of $7 \mathrm{~cm}$. The liquid source inside each chamber has diameter and height of $5 \mathrm{~cm}$ and $0.8 \mathrm{~cm}$, respectively. Since we use a 1D model, we define a length scale $L$ for each chamber with the following formula: $L=\left(V_{\text {chamber }}-V_{\text {source }}\right) / A_{\text {source, }}$ where the numerator reflects the unoccupied volume of the chamber and the denominator is the surface area of the liquid source. We find $L=0.75 \mathrm{~cm}$ for the small chamber, and $L=19 \mathrm{~cm}$ for the large chamber. 

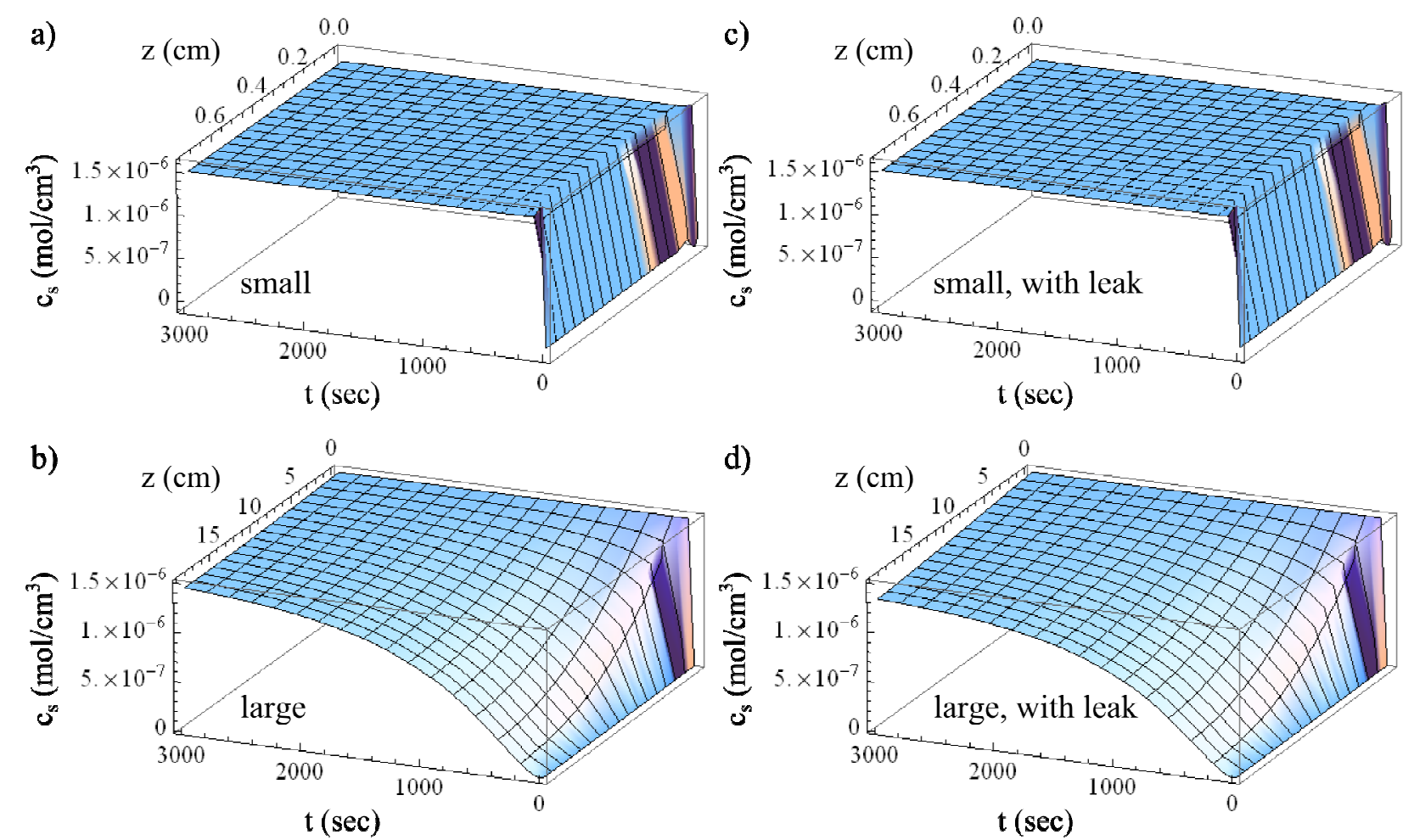

Figure 3: Toluene concentration in the vapor phase $c_{s}$ as a function of $t$ and $z$ for a) small chamber; b) large chamber; c) leaky small chamber; d) leaky large chamber.

Figures 3a and 3b summarize the transient concentration profiles from $z=0$ to $L$ over 3000 sec. The small chamber is filled with vapor at a partial pressure of $p_{\mathrm{s}}=P^{\text {vap }}$ within 10 seconds. However, the large chamber requires nearly an hour to reach the same steady-state concentration. This model suggests that slow ordering kinetics in the large chamber is at least partly associated with the long time scales to achieve a saturated vapor phase.

Another point to consider is the solvent leakage rate. Each chamber is merely an upsidedown glass dish placed on the bottom of the glove box, meaning there is no seal at the base. The gradient in solvent composition could drive diffusion out of the chamber into the large glove box, where the ambient solvent composition is approximately 0 . Therefore, the third boundary condition might be better described as:

$$
\left.\frac{\partial c_{s}}{\partial z}\right|_{z=L}=-C s[t, L] * \text { constant }
$$


The constant captures the effective solvent diffusivity $\left(D_{\text {eff }}\right)$ through the narrow gap and the mass transfer coefficient $\left(k_{c}\right)$ for diffusion of solvent inside the glove box (as the surrounding gas is not stagnant). It is difficult to estimate these parameters for the present system, so we assume the constant is approximately $k_{c} / D_{\text {eff }}=0.005$. Outcomes are reported in Figures 3c and 3d. The transient concentration profiles in the small chamber are largely unaffected by a small leak, while the large chamber does not reach a concentration of $1.5 \times 10^{-6} \mathrm{~mol} / \mathrm{cm}^{3}$ within 3000 seconds. If we increase the constant by an order of magnitude, producing a bigger leak, then we find an even larger discrepancy between the two chambers in the long time limit. This is illustrated by Figure $\mathbf{S 4}$ in the supporting information.

The second challenge to address was replace toluene with industry-benign solvents (MEK and PGMEA) to see whether the same degree of surface order could be attained. Following the previously discussed methods, we can predict the saturation time for each solvent system in the small and large chambers. For MEK, the vapor pressure is 0.126 bar at $298 \mathrm{~K}$, so $c_{s}[t, 0]=$ $5.1 \times 10^{-6} \mathrm{~mol} / \mathrm{cm}^{3}$. The diffusivity of MEK in air is approximately $0.24 \mathrm{~cm}^{2} / \mathrm{sec}$.[58] For PGMEA, the vapor pressure is 0.007 bar at $298 \mathrm{~K}$, so $c_{s}[t, 0]=2.7 \times 10^{-7} \mathrm{~mol} / \mathrm{cm}^{3}$. The diffusivity of PGMEA in air is approximately $0.17 \mathrm{~cm}^{2} / \mathrm{sec}$.[58] Figure 4 reports the time required to achieve a saturated vapor state. The saturation time is very fast (nearly instantaneous) for both solvents in the small chamber, while saturation is slow in the large chamber. However, as discussed in Table 3, the solvent concentration in the film is much higher for MEK than PGMEA, so we do not anticipate similar ordering kinetics in the two systems. 

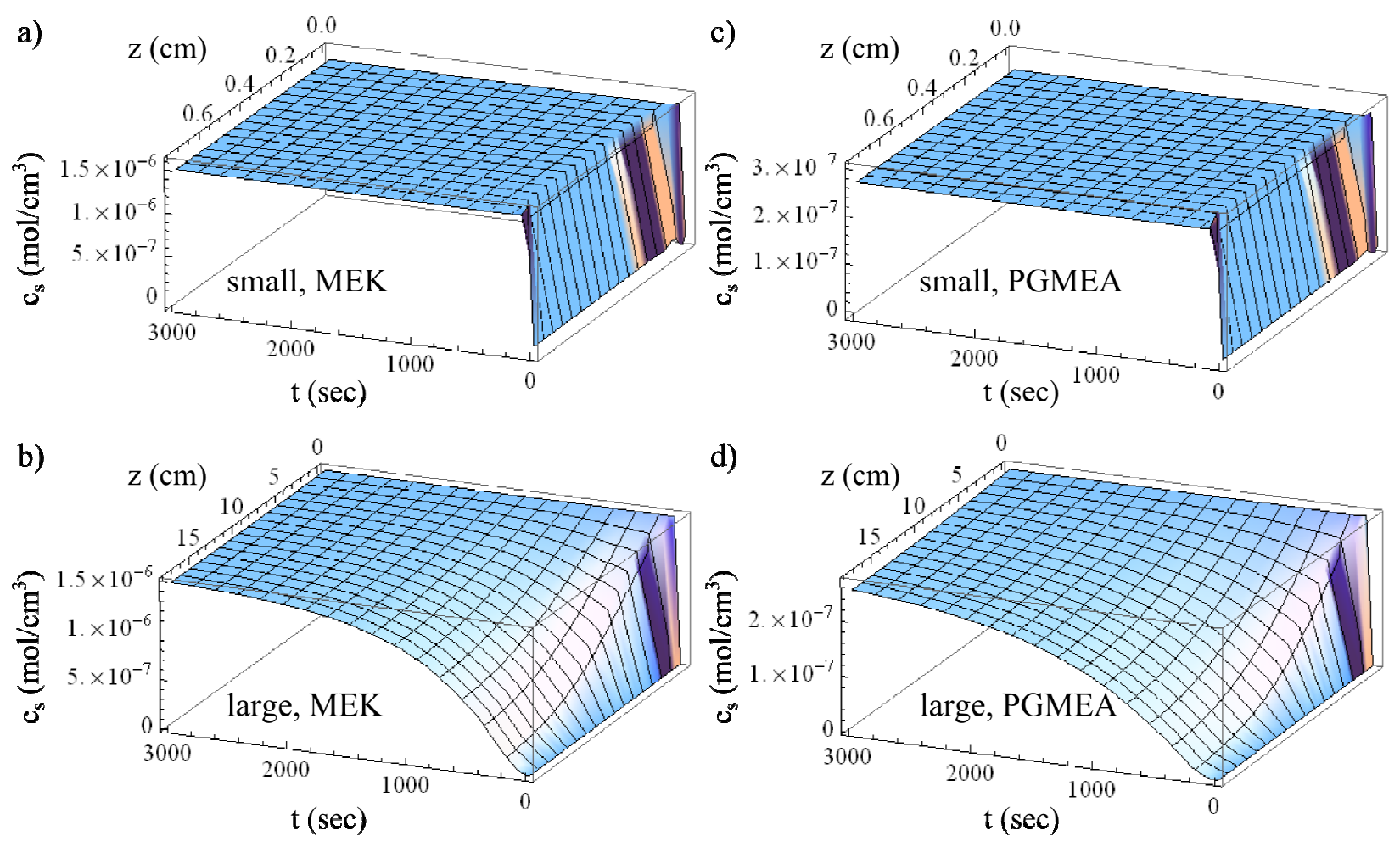

Figure 4: Solvent concentration $c_{s}$ as a function of $t$ and $z$ for a) small chamber with MEK; b) large chamber with MEK; c) small chamber with PGMEA; d) large chamber with PGMEA.

Table 5 summarizes the experimental conditions and results for the annealing process under MEK. All films annealed under MEK were allowed de-swell time for 5 minutes. As shown in Figure 5A, annealing times less than 3 hours in the small chamber produced parallel cylinders with $d=23 \mathrm{~nm}$. Annealing times in excess of 12 hours in the small chamber produced ordered hexagonal domains at the surface of the film with grain sizes of approximately $0.70 \mu \mathrm{m} \times 0.70$ $\mu \mathrm{m}$ and $d=23 \mathrm{~nm}$, although the surface was rough (Figure 5B). An increase in annealing time to 18 hours in the small chamber showed significantly improved ordering, with highly ordered hexagonal domains on the surface having an average of grain size about $1.6 \mu \mathrm{m} \times 1.6 \mu \mathrm{m}$ and $d$ $=25 \mathrm{~nm}$ (Figure 5C). The results for the smaller chamber were much better than those for the large chamber with 18 hours of annealing, where the latter case produced poorly ordered hexagonal domains with $d=30 \mathrm{~nm}$. The domains at the film surface had non-uniform sizes and many pinhole defects (Figure 5D). 
The parallel cylinders shown in Figure 5A could be caused by the different surface energy of PEO and PS segments under humid MEK vapor, as this solvent environment is selective to PEO. The pitch $d$ for parallel and perpendicular cylinders are the distance between nearest-neighbors and the distance between close-packed rows, respectively. Therefore, if the cylinders re-orient normal to the film with increased annealing time, then the d-spacing is reduced by a factor of $\sqrt{ } 3 / 2$. Such behavior is not observed here, which suggests that the ordered surface structure is in fact "perforations" rather than vertical cylinders.

Like the case of toluene, the time required to achieve large grains is reduced with decreasing chamber size. However, the time scales to reach grain sizes on the order of $1 \mu \mathrm{m}^{2}$ are longer than achieved with toluene. As summarized in Tables 2 and 3, the uptake of MEK in the film is larger than that of toluene, even though MEK is less soluble than toluene in PS. This is associated with the higher $P^{v a p}$ at $25^{\circ} \mathrm{C}$ of MEK compared with toluene. Therefore, we conclude that kinetics of ordering is suppressed because MEK enhances the compatibility between PEO and PS.[59-62] Another interesting point is that changes in $d$ as a function of annealing time and chamber size are consistent with toluene: $d$ ranges from 23 to $25 \mathrm{~nm}$ in the small chamber, while $d$ reaches 30 $\mathrm{nm}$ at long times in the large chamber (Figure S7). 
Table 5: Annealing conditions and results for PEO- $b$-PS thin films in large and small chambers with MEK as annealing solvent. "Disordered" grain size consists of both parallel and perpendicular domains on the surface with no degree of ordering to determine average grain size, " $=$ " means cylinders parallel to the surface, “ $\perp$ ” means hexagonally-packed domains on the surface. Average grain size depicts the size of continuous ordered grains in the AFM micrographs only if perpendicular or parallel domains were present. De-swelling time $=5 \mathrm{~min}$.

\begin{tabular}{|c|c|c|c|c|c|}
\hline Sample & $\begin{array}{c}\text { Chamber Size } \\
\text { (Volume) }\end{array}$ & $\begin{array}{c}\text { Annealing } \\
\text { Time }\end{array}$ & $\begin{array}{c}\text { Relative } \\
\text { Humidity }\end{array}$ & d (nm) & Average Grain Size \\
\hline $1 \mathrm{a}$ & $1236 \mathrm{~cm}^{3}$ & 0.5 hour & $88 \%$ & 23 & Disordered \\
\hline $1 b$ & $1236 \mathrm{~cm}^{3}$ & 1 hour & $89 \%$ & 23 & Disordered \\
\hline $1 \mathrm{c}$ & $1236 \mathrm{~cm}^{3}$ & 3 hours & $88 \%$ & 24 & Disordered \\
\hline $1 d$ & $1236 \mathrm{~cm}^{3}$ & 6 hours & $90 \%$ & 25 & “上”, $0.20 \mu \mathrm{m} \times 0.20 \mu \mathrm{m}$ \\
\hline $1 \mathrm{e}$ & $1236 \mathrm{~cm}^{3}$ & 18 hours & $90 \%$ & 30 & “上”, $0.70 \mu \mathrm{m} \times 0.70 \mu \mathrm{m}$ \\
\hline $2 \mathrm{a}$ & $64 \mathrm{~cm}^{3}$ & 0.5 hour & $88 \%$ & 23 & Disordered \\
\hline $2 b$ & $64 \mathrm{~cm}^{3}$ & 1 hour & $89 \%$ & 23 & Disordered \\
\hline $2 \mathrm{c}$ & $64 \mathrm{~cm}^{3}$ & 3 hours & $88 \%$ & 23 & $"=", 0.30 \mu \mathrm{m} \times 0.30 \mu \mathrm{m}$ \\
\hline $2 \mathrm{~d}$ & $64 \mathrm{~cm}^{3}$ & 6 hours & $90 \%$ & 23 & “上”, $0.35 \mu \mathrm{m} \times 0.35 \mu \mathrm{m}$ \\
\hline $2 \mathrm{e}$ & $64 \mathrm{~cm}^{3}$ & 12 hours & $88 \%$ & 23 & “卫”, $0.70 \mu \mathrm{m} \times 0.70 \mu \mathrm{m}$ \\
\hline $2 f$ & $64 \mathrm{~cm}^{3}$ & 16 hours & $88 \%$ & 24 & “L”, $0.80 \mu \mathrm{m} \times 0.80 \mu \mathrm{m}$ \\
\hline $2 \mathrm{~g}$ & $64 \mathrm{~cm}^{3}$ & 18 hours & $88 \%$ & 25 & "L", $1.60 \mu \mathrm{m} \times 1.60 \mu \mathrm{m}$ \\
\hline
\end{tabular}



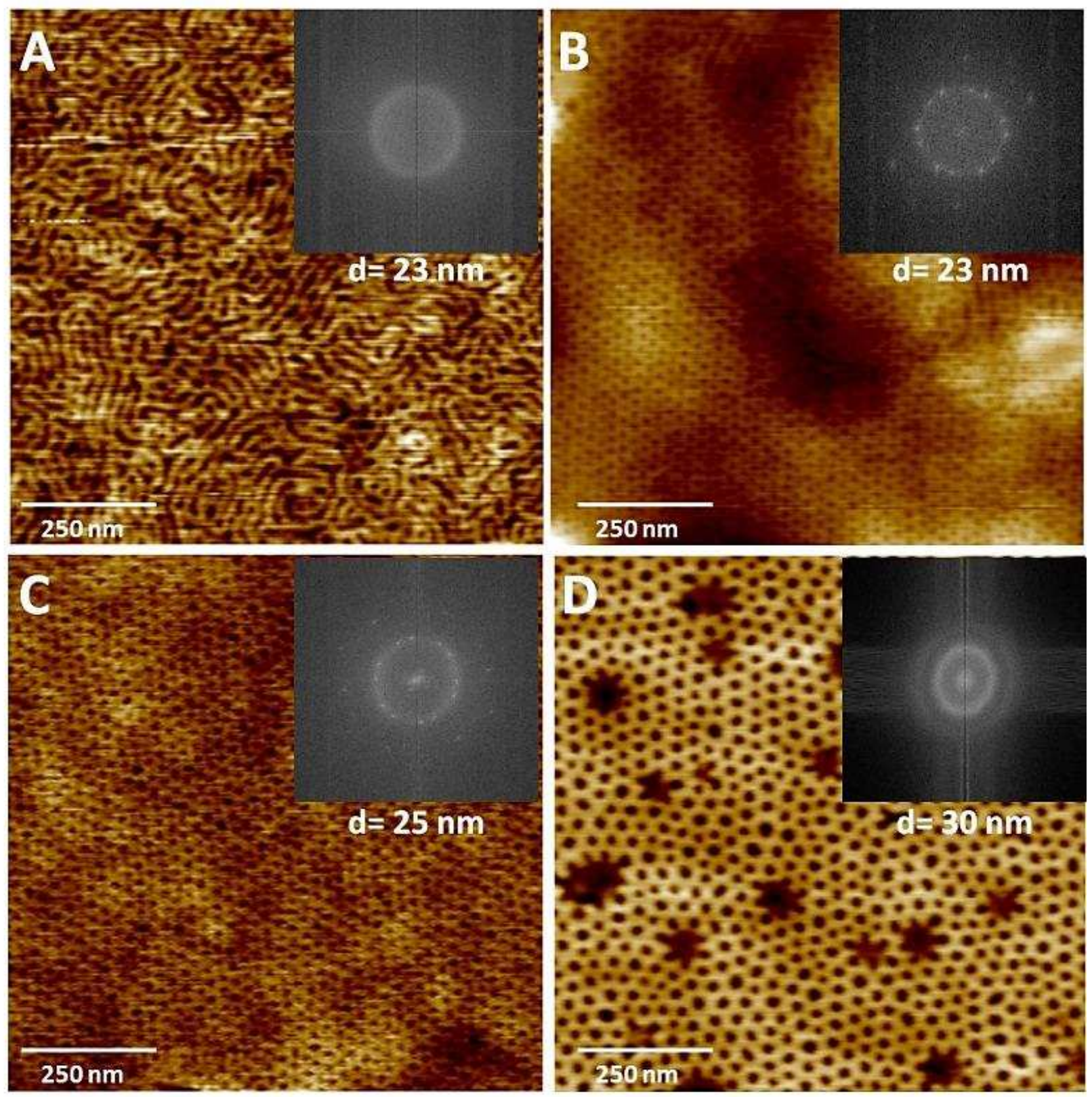

Figure 5: AFM height images of thin films of block copolymer PEO- $b$-PS processed by solvent annealing under MEK: Effect of annealing time $(\mathrm{A}=\mathbf{2 c}$, small chamber, $3 \mathrm{hr} ; \mathrm{B}=\mathbf{2 e}$, small chamber, $12 \mathrm{hr} ; \mathrm{C}=\mathbf{2 g}$, small chamber, $18 \mathrm{hr}$; $\mathrm{D}=\mathbf{1 e}$, large chamber, $18 \mathrm{hr}$ ).

Next we carried out solvent annealing with PGMEA vapor. Table 6 summarizes the experimental conditions and results. When the film was annealed for 18 hours under PGMEA in the large chamber, but de-swelled for only 5 minutes, the films were characterized by parallel cylinders with $d=26 \mathrm{~nm}$ (Figure 6A). When the de-swelling time was increased from $5 \mathrm{~min}$ to 2.5 hours, disordered hexagonal domains with an average grain size of $0.7 \mu \mathrm{m} \times 0.7 \mu \mathrm{m}$ and $d=$ 
$27 \mathrm{~nm}$ were observed at the film surface (Figure 6B). A long solvent annealing time in the small chamber ( 20 hours) with a long de-swelling time (2.5 hours) generated a highly ordered film with hexagonally packed domains, which have an average grain size of $1.6 \mu \mathrm{m} \times 1.6 \mu \mathrm{m}$ and $d=$ $29 \mathrm{~nm}$ as shown in Figure 6C. When the de-swell time was kept at 2.5 hour, but the annealing time was decreased to 6 hours, the films exhibit hexagonally-packed domains with an average grain size of $0.4 \mu \mathrm{m} \times 0.4 \mu \mathrm{m}$ and $d=28 \mathrm{~nm}$ (Figure 6D). As shown in Figure 4, saturation time is very fast for both solvents in the small chamber. However, as summarized in Tables 2 and 3, the uptake of PGMEA in the film is much lower than that of MEK and toluene. This is associated with the lower $P^{v a p}$ at $25^{\circ} \mathrm{C}$ of PGMEA compared with the other two solvents. Also, the diffusivity of PGMEA $\left(0.17 \mathrm{~cm}^{2} / \mathrm{sec}\right)$ compared with MEK $\left(0.24 \mathrm{~cm}^{2} / \mathrm{sec}\right)$, and toluene $(0.2$ $\left.\mathrm{cm}^{2} / \mathrm{sec}\right)$ is much lower. This contributes to the longer de-swell time needed for PGMEA rather than MEK and toluene, since there is little solvent in the film, so when evaporation occurs there is not much cooling at the surface which drives water condensation on the film. 
Table 6: Annealing conditions and results for PEO- $b$-PS block copolymer thin films in large and small chambers with PGMEA as annealing solvent. "Disordered" grain size consists of both parallel and perpendicular domains on the surface with no degree of ordering to determine average grain size. " $=$ " means cylinders parallel to the surface, “ $\perp$ ” means hexagonally-packed domains on the surface. Average grain size depicts the size of continuous ordered grains in the AFM micrographs only if perpendicular or parallel domains were present.

\begin{tabular}{|c|c|c|c|c|c|c|}
\hline Sample & $\begin{array}{c}\text { Chamber } \\
\text { Size } \\
\text { (Volume) }\end{array}$ & $\begin{array}{c}\text { Annealing } \\
\text { Time }\end{array}$ & $\begin{array}{c}\text { De- } \\
\text { swelling } \\
\text { Time }\end{array}$ & $\begin{array}{c}\text { Relative } \\
\text { Humidity }\end{array}$ & d (nm) & Average Grain Size \\
\hline $1 \mathrm{a}$ & $1236 \mathrm{~cm}^{3}$ & 0.5 hour & 2.5 hours & $92 \%$ & 23 & Disordered \\
\hline $1 b$ & $1236 \mathrm{~cm}^{3}$ & 1 hour & 2.5 hours & $92 \%$ & 23 & Disordered \\
\hline $1 \mathrm{c}$ & $1236 \mathrm{~cm}^{3}$ & 3 hours & 2.5 hours & $92 \%$ & 24 & Disordered \\
\hline $1 \mathrm{~d}$ & $1236 \mathrm{~cm}^{3}$ & 18 hours & $5 \mathrm{~min}$ & $92 \%$ & 26 & " $=", 1.1 \mu \mathrm{m} \times 1.1 \mu \mathrm{m}$ \\
\hline $1 \mathrm{e}$ & $1236 \mathrm{~cm}^{3}$ & 18 hours & 2.5 hours & $92 \%$ & 27 & 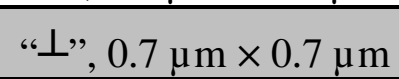 \\
\hline $2 \mathrm{a}$ & $64 \mathrm{~cm}^{3}$ & 0.5 hour & 2.5 hours & $92 \%$ & 22 & Disordered \\
\hline $2 \mathrm{~b}$ & $64 \mathrm{~cm}^{3}$ & 1 hour & 2.5 hours & $92 \%$ & 22 & Disordered \\
\hline $2 \mathrm{c}$ & $64 \mathrm{~cm}^{3}$ & 3 hours & 2.5 hours & $92 \%$ & 22 & 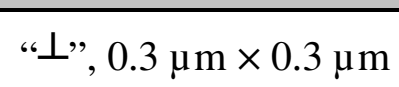 \\
\hline $2 \mathrm{~d}$ & $64 \mathrm{~cm}^{3}$ & 6 hours & 2.5 hours & $92 \%$ & 27 & 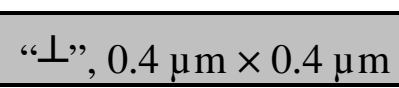 \\
\hline $2 \mathrm{e}$ & $64 \mathrm{~cm}^{3}$ & 12 hours & 2.5 hours & $92 \%$ & 27 & “上”, $0.5 \mu \mathrm{m} \times 0.5 \mu \mathrm{m}$ \\
\hline $2 \mathrm{f}$ & $64 \mathrm{~cm}^{3}$ & 20 hours & 2.5 hours & $92 \%$ & 29 & "上", $1.6 \mu \mathrm{m} \times 1.6 \mu \mathrm{m}$ \\
\hline
\end{tabular}



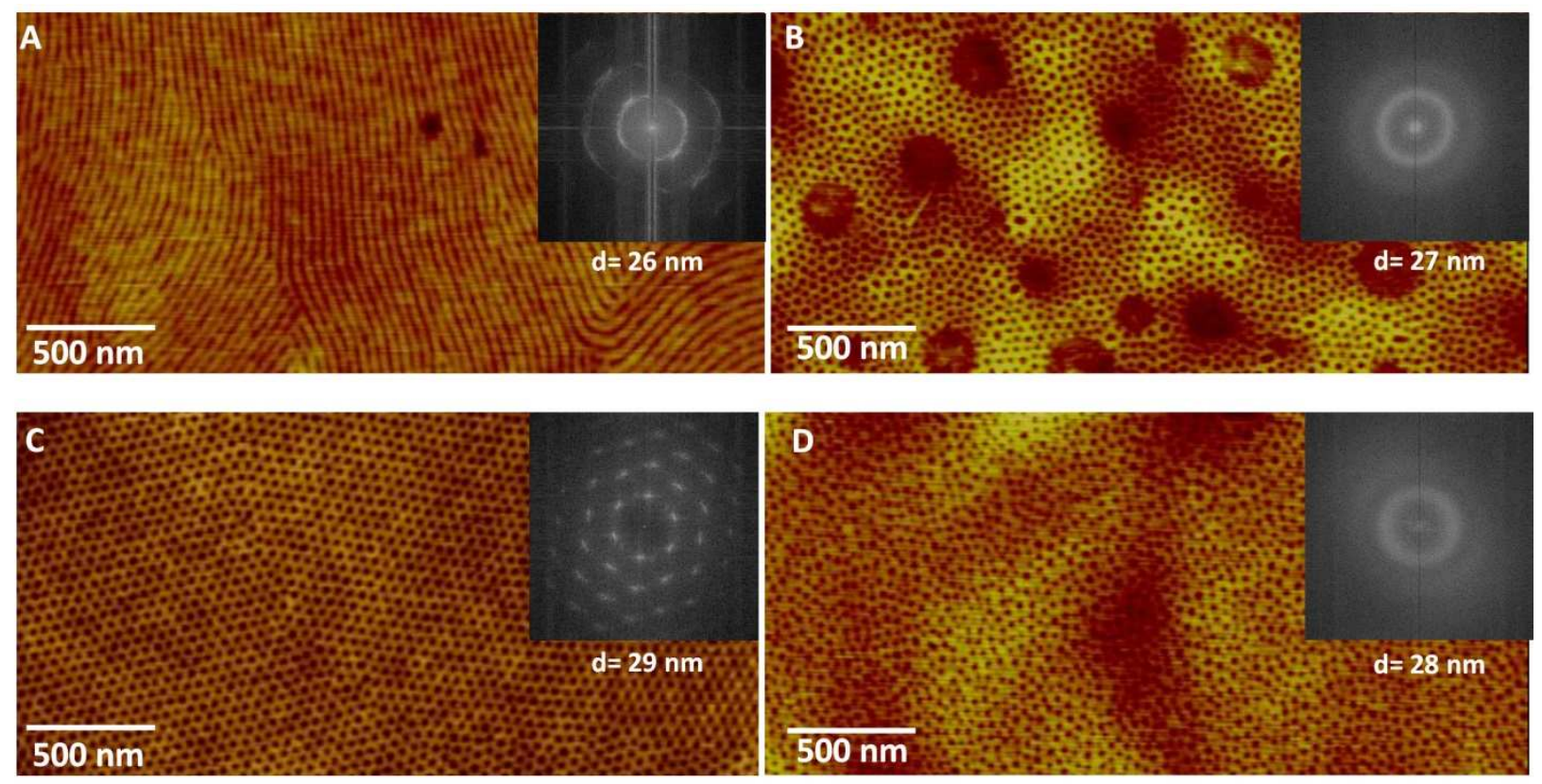

Figure 6: AFM height images of thin films of block copolymer PEO- $b$-PS processed by solvent annealing under PGMEA: Effect of annealing time $(\mathrm{A}=\mathbf{1 d}$, large chamber, $18 \mathrm{hr}, 5 \mathrm{~min}$ deswell; B = 1e, large chamber, $18 \mathrm{hr}, 2.5 \mathrm{hr}$ de-swell; $\mathrm{C}=\mathbf{2 f}$, small chamber, 20hr, $2.5 \mathrm{hr}$ deswell; D = 2d, small chamber, $6 \mathrm{hr}, 2.5 \mathrm{hr}$ de-swell).

GISAXS measurements were performed to evaluate ordering induced by the highhumidity solvent annealing processes. Films were measured by varying the incident angle near the polymer's critical angle $\left(\alpha_{c} \approx 0.16^{\circ}\right)$, which produces controlled X-ray penetration depths in the range of $10 \mathrm{~nm}$ up to the full film thickness.[63]

For the first set of experiments, films were annealed in toluene using the small chamber for 3 hours, and then de-swelled under high humidity for $15 \mathrm{~min}$. This corresponds to Sample $2 \mathrm{~d}$ in Table 4 and Figure 1D. The scattering profiles recorded above and below the polymer's critical angle are nearly identical (Figure 7). If perpendicular cylinders persist throughout the film thickness, then the in-plane first-order diffraction rod should exhibit "oscillations" with a period that is inversely proportional to the cylinder height (i.e., the form factor).[64, 65] Instead, we observe a broad "streak" along the $\alpha_{\mathrm{f}}$ axis at all incident angles, meaning a thin surface structure is dominating the scattering. The symmetry of the surface structure is hexagonal, which is determined from the relative positions of the first- and second-order in-plane scattering peaks $(1: \sqrt{ } 3)$. The distance between close-packed rows in the hexagonal lattice is approximately $d=30 \mathrm{~nm}$, which is a few nanometers larger than AFM measurements. It is important to note 
that the $\sqrt{ } 3$ peak is not detected at low values of $\alpha_{\mathrm{f}}$, which is a signature of surface scattering from "dimples". This point is further discussed at the end of the GISAXS discussion.
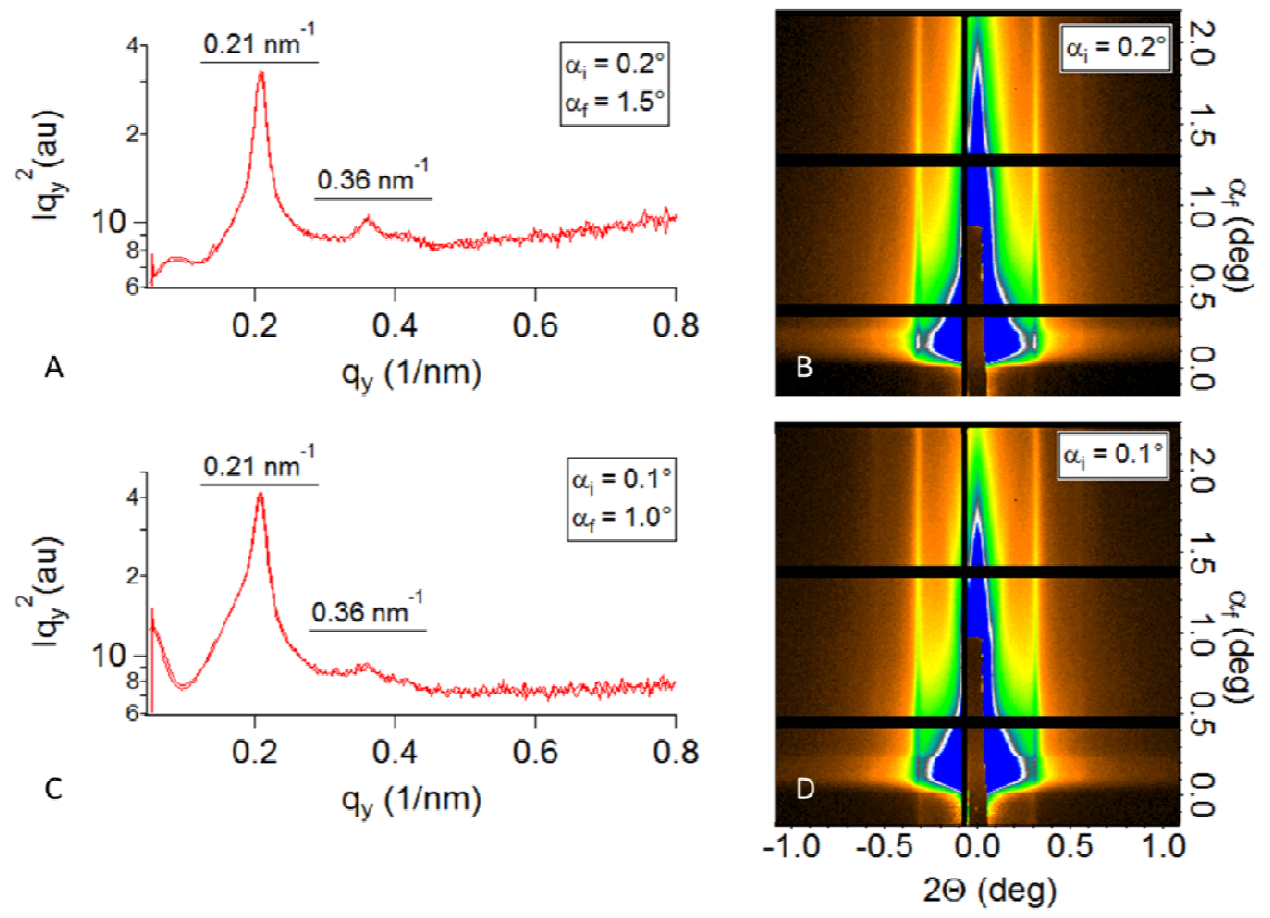

Figure 7: GISAXS measurement of films with toluene solvent annealing: $(A, B)$ above the polymer's critical angle, sampling the full film thickness; (C,D) below the polymer's critical angle, sampling the top $\sim 10 \mathrm{~nm}$.

For the second set of experiments, films were annealed in MEK using the small chamber for 18 hours, and then de-swelled under high humidity for $5 \mathrm{~min}$. This corresponds to Sample $2 \mathrm{~g}$ in Table 5 and Figure 5C. Much like the samples annealed in toluene, the scattering profiles recorded above and below the polymer's critical angle are nearly identical, and there is no sign of perpendicular cylinders that persist throughout the film's thickness (Figure 8). However, the in-plane symmetry is consistent with parallel cylinders, which is determined from the relative positions of first- and second-order in-plane scattering peaks (1:2). The cylinder-to-cylinder distance is approximately $d=25 \mathrm{~nm}$, which is two nanometers larger than the AFM measurement of parallel cylinders. There is no evidence of layering, which means there is not a complete unit cell (at most two layers of cylinders). Note that the second order peak is only detected at exit angles near the polymer's critical angle $\left(\alpha_{\mathrm{f}} \approx 1.2 \alpha_{\mathrm{c}}\right)$. 
For the final set of experiments, films were annealed in PGMEA using the small chamber for 20 hours, and de-swelled for 2.5 hours. This condition corresponds to Sample $2 \mathrm{f}$ in Table 6 and Figure 6C. The scattering profiles (Figure 9) are very similar to the case of toluene solvent annealing, but with the appearance of higher order in-plane peaks (ratios of $1: \sqrt{ } 3: \sqrt{ } 4: \sqrt{ } 7$ ). The distance between close-packed rows is approximately $29 \mathrm{~nm}$, which is nearly identical to the outcomes of toluene solvent annealing and matches the AFM data. The improvement in lateral order makes it easier to see the out-of-plane structure. For example, in Figure 8D, it is clear that the $\sqrt{ } 3$ peak is strongest near $\alpha_{\mathrm{f}} \approx 1^{\mathrm{o}}$. The solid pink line is a guide to eye that marks the maxima of in-plane peaks, and this demonstrates that the surface structure has "sloped" sidewalls $(\gamma \approx$ $30^{\circ}$ ), meaning the PEO domains have collapsed to form a "dimpled" surface.[46]
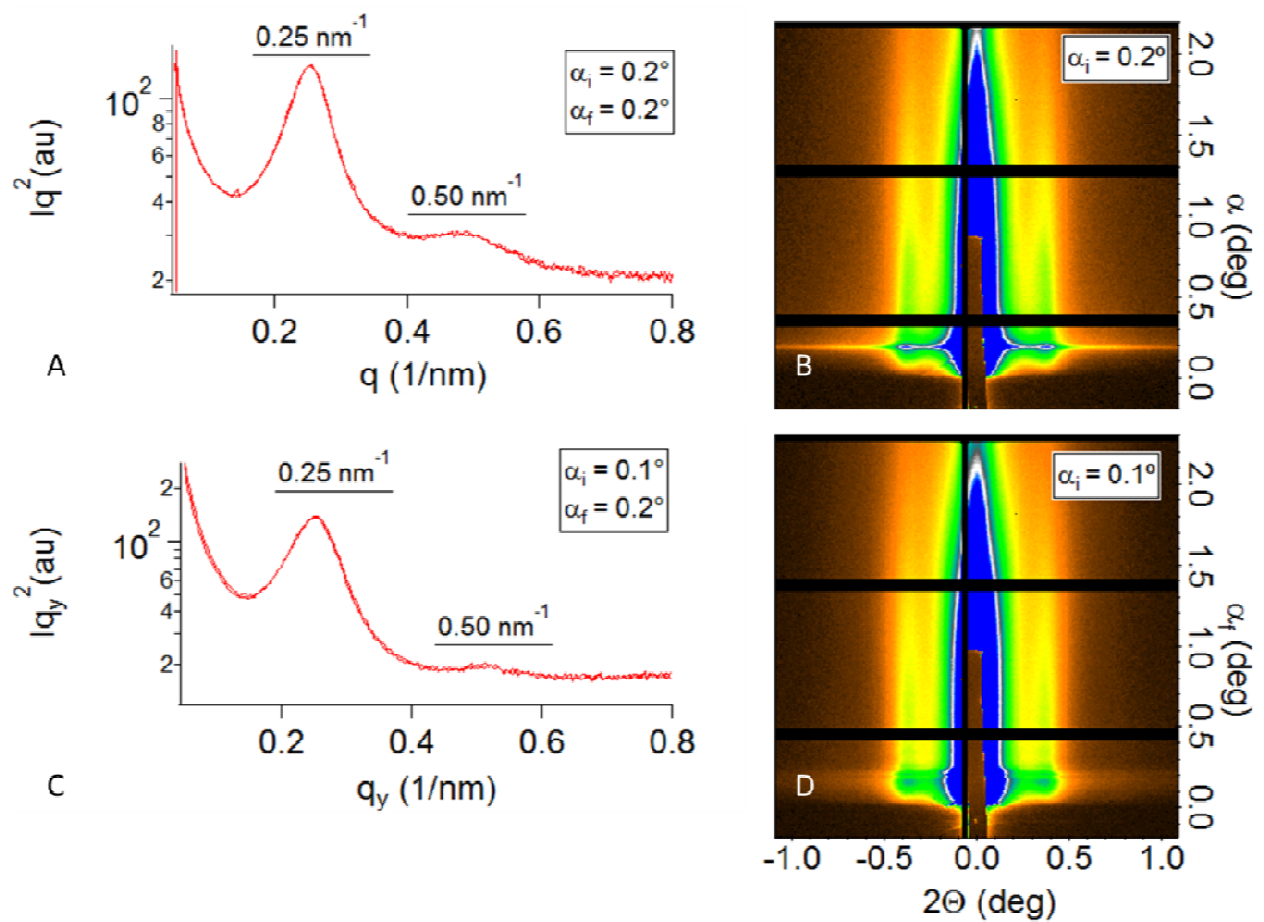

Figure 8: GISAXS measurement of films by solvent annealing under MEK: $(A, B)$ above the polymer's critical angle, sampling the full film thickness; (C,D) below the polymer's critical angle, sampling the top $\sim 10 \mathrm{~nm}$. 

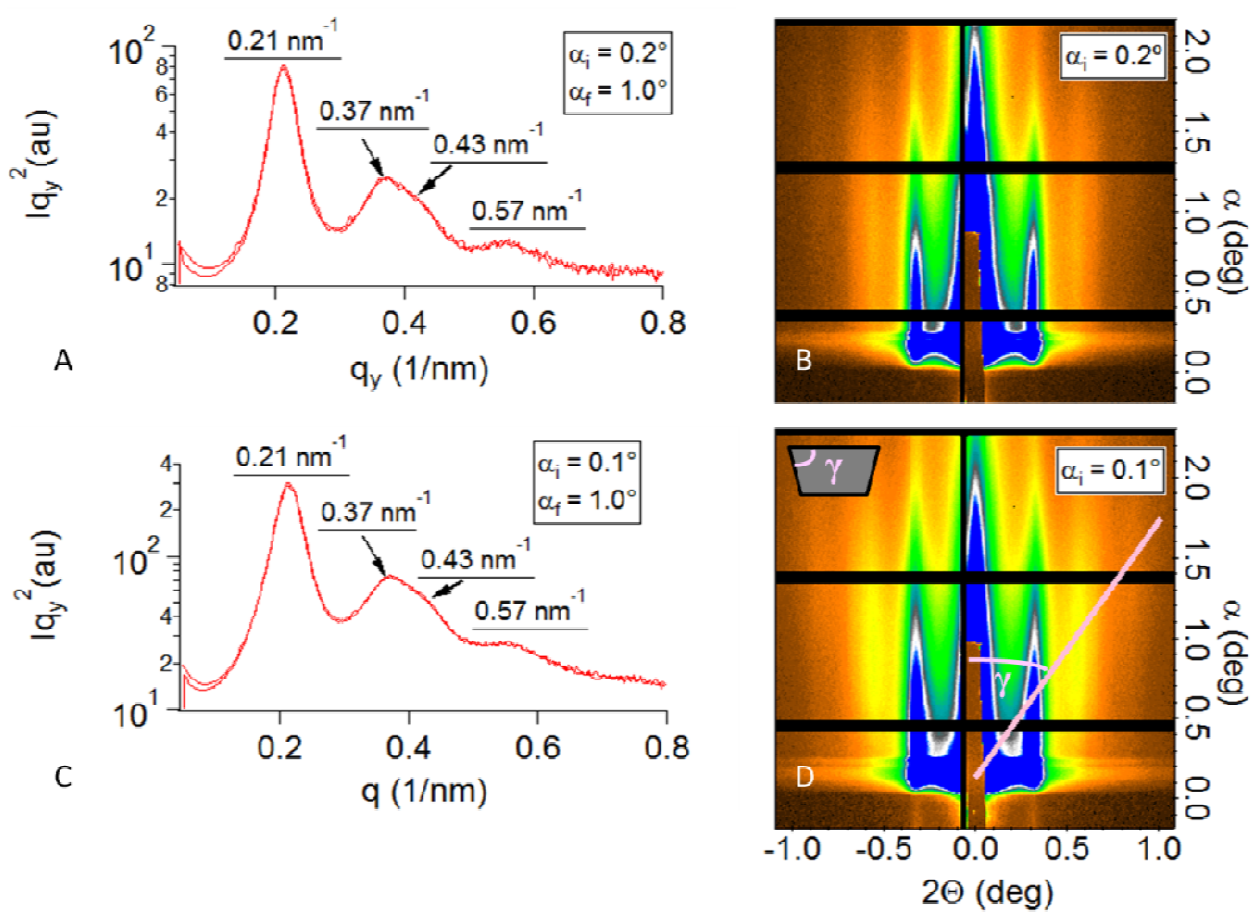

Figure 9: GISAXS measurement of films by solvent annealing under PGMEA: $(A, B)$ above the polymer's critical angle, sampling the full film thickness; (C,D) below the polymer' critical angle, sampling the top $\sim 10 \mathrm{~nm}$.

Both AFM and GISAXS data suggest the lattice parameter for the PEO-b-PS block copolymer ranges from $23 \mathrm{~nm}$ to $30 \mathrm{~nm}$ depending on the solvent, annealing time, and lattice symmetry (hexagonal or parallel cylinders). It is important to note that transitions from parallel cylinders to hexagonal order are observed in both MEK and PGMEA processes, and these structures have nearly the same row-to-row spacing. If the hexagonal surface patterns are associated with perpendicular cylinders, then the row-to-row spacing should be $\sqrt{ } 3 / 2$ of the parallel cylinder-to-cylinder distance. Therefore, we conclude that hexagonal dimples at the film surface are a result of parallel cylinders that perforate at the top. GISAXS results are dominated by scattering from the dimpled surface, but the data are consistent with the AFM measurements: the peaks from cylinders will overlap with the hexagonal structure at 1 and $\sqrt{ } 4$. Scheme 2 illustrates the proposed surface structure of PEO- $b$-PS thin films solvent annealed under high humidity. 
Scheme 2. Proposed surface structure of block copolymer PEO- $b$-PS thin films solvent annealed under high humidity. Pink = PEO; Green $=$ PS.

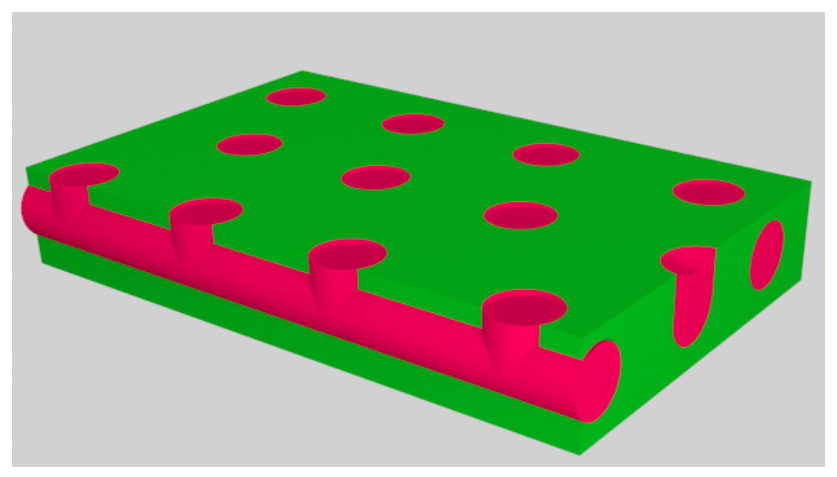

\section{Conclusions}

We investigated high humidity solvent annealing in thin films of amphilic PEO- $b$-PS block copolymers. Using toluene solvent we reduced the annealing time from hours to minutes by decreasing the chamber volume to reduce the saturation time. We then evaluated the benign solvents MEK and PGMEA and showed that both can drive ordering, but they are less effective than toluene because they enhance the compatibility between PS and PEO segments. The combination of AFM and GISAXS data suggest that hexagonal domains at the polymer/air interface do not propagate throughout the thickness of the film. The lattice periodicity increases in each solvent environment as a function of time, a challenge that is apparently mitigated by use of the small annealing chamber.

\section{Acknowledgements}

This work was supported by Global Research Collaboration Program of Semiconductor Research Corporation (Task ID 2222.001, to C. Tang) and the National Science Foundation (DMR115146, to G.E. Stein). Acknowledgment is made to the donors of the American Chemical Society Petroleum Research Fund for partial support of this research (Doctoral New Investigator Award, to C. Tang). Use of the Advanced Photon Source, an Office of Science User Facility operated for the U.S. Department of Energy (DOE) Office of Science by Argonne National Laboratory, was supported by the U.S. DOE under Contract No. DE-AC02-06CH11357. 


\section{References:}

[1] Bates FS. Polymer-Polymer Phase Behavior. Science 1991;251:898-905.

[2] Fredrickson GH, Bates FS. Dynamics of Block Copolymers: Theory and Experiment. Annu Rev Mater Sci 1996;26:501-50.

[3] Bates FS, Hillmyer MA, Lodge TP, Bates CM, Delaney KT, Fredrickson GH. Multiblock Polymers: Panacea or Pandora's Box? Science 2012;336:434-40.

[4] Hawker CJ, Wooley KL. The Convergence of Synthetic Organic and Polymer Chemistries. Science 2005;309:1200-5.

[5] Stuparu MC, Khan A, Hawker CJ. Phase separation of supramolecular and dynamic block copolymers. Polym Chem 2012;3:3033-44.

[6] Bates FS, Fredrickson GH. Block Copolymers---Designer Soft Materials. Phys Today 1999;52:32-8.

[7] Bates CM, Maher MJ, Janes DW, Ellison CJ, Willson CG. Block Copolymer Lithography. Macromolecules 2013;47:2-12.

[8] Park M, Harrison C, Chaikin PM, Register RA, Adamson DH. Block Copolymer Lithography: Periodic Arrays of 1011 Holes in 1 Square Centimeter. Science 1997;276:1401-4.

[9] Hawker CJ, Russell TP. Block Copolymer Lithography: Merging "Bottom-Up” with “TopDown” Processes. MRS Bull 2005;30:952-66.

[10] Luo M, Epps TH. Directed Block Copolymer Thin Film Self-Assembly: Emerging Trends in Nanopattern Fabrication. Macromolecules 2013;46:7567-79.

[11] Hardy CG, Tang C. Advances in square arrays through self-assembly and directed selfassembly of block copolymers. J Polym Sci Part B: Polym Phys 2013;51:2-15.

[12] Kempe K, Killops KL, Poelma JE, Jung H, Bang J, Hoogenboom R, et al. Strongly PhaseSegregating Block Copolymers with Sub-20 nm Features. ACS Macro Lett 2013;2:677-82.

[13] Kim HC, Jia X, Stafford CM, Kim DH, McCarthy TJ, Tuominen M, et al. A Route to Nanoscopic SiO2 Posts via Block Copolymer Templates. Adv Mater 2001;13:795-7.

[14] Kim DH, Kim SH, Lavery K, Russell TP. Inorganic Nanodots from Thin Films of Block Copolymers. Nano Lett 2004;4:1841-4.

[15] Thurn-Albrecht T, Schotter J, Kästle GA, Emley N, Shibauchi T, Krusin-Elbaum L, et al. Ultrahigh-Density Nanowire Arrays Grown in Self-Assembled Diblock Copolymer Templates. Science 2000;290:2126-9.

[16] Cheng JY, Ross CA, Chan VZH, Thomas EL, Lammertink RGH, Vancso GJ. Formation of a Cobalt Magnetic Dot Array via Block Copolymer Lithography. Adv Mater 2001;13:1174-8.

[17] Park S, Lee DH, Xu J, Kim B, Hong SW, Jeong U, et al. Macroscopic 10-Terabit-perSquare-Inch Arrays from Block Copolymers with Lateral Order. Science 2009;323:1030-3.

[18] Bao X-Y, Yi H, Bencher C, Chang L-W, Dai H, Chen Y, et al. SRAM, NAND, DRAM contact hole patterning using block copolymer directed self-assembly guided by small topographical templates. Electron Devices Meeting (IEDM), 2011 IEEE International 2011:7..17..4.

[19] Mansky P, DeRouchey J, Russell TP, Mays J, Pitsikalis M, Morkved T, et al. Large-Area Domain Alignment in Block Copolymer Thin Films Using Electric Fields. Macromolecules 1998;31:4399-401. 
[20] Mansky P, Liu Y, Huang E, Russell TP, Hawker C. Controlling Polymer-Surface Interactions with Random Copolymer Brushes. Science 1997;275:1458-60.

[21] Morkved TL, Lu M, Urbas AM, Ehrichs EE, Jaeger HM, Mansky P, et al. Local Control of Microdomain Orientation in Diblock Copolymer Thin Films with Electric Fields. Science 1996;273:931-3.

[22] Tang C, Wu W, Smilgies D-M, Matyjaszewski K, Kowalewski T. Robust Control of Microdomain Orientation in Thin Films of Block Copolymers by Zone Casting. J Am Chem Soc 2011;133:11802-9.

[23] Ouk Kim S, Solak HH, Stoykovich MP, Ferrier NJ, de Pablo JJ, Nealey PF. Epitaxial selfassembly of block copolymers on lithographically defined nanopatterned substrates. Nature 2003;424:411-4.

[24] Rockford L, Mochrie SGJ, Russell TP. Propagation of Nanopatterned Substrate Templated Ordering of Block Copolymers in Thick Films. Macromolecules 2001;34:1487-92.

[25] Segalman RA, Yokoyama H, Kramer EJ. Graphoepitaxy of Spherical Domain Block Copolymer Films. Adv Mater 2001;13:1152-5.

[26] Stein GE, Kramer EJ, Li X, Wang J. Single-Crystal Diffraction from Two-Dimensional Block Copolymer Arrays. Phys Rev Lett 2007;98:086101.

[27] Sinturel C, Vayer M, Morris M, Hillmyer MA. Solvent Vapor Annealing of Block Polymer Thin Films. Macromolecules 2013;46:5399-415.

[28] Jung YS, Ross CA. Solvent-Vapor-Induced Tunability of Self-Assembled Block Copolymer Patterns. Adv Mater 2009;21:2540-5.

[29] Lin ZQ, Kim DH, Wu XD, Boosahda L, Stone D, LaRose L, et al. A Rapid Route to Arrays of Nanostructures in Thin Films. Adv Mater 2002;14:1373-6.

[30] Jung YS, Chang JB, Verploegen E, Berggren KK, Ross CA. A Path to Ultranarrow Patterns Using Self-Assembled Lithography. Nano Lett 2010;10:1000-5.

[31] Gotrik KW, Hannon AF, Son JG, Keller B, Alexander-Katz A, Ross CA. Morphology Control in Block Copolymer Films Using Mixed Solvent Vapors. ACS Nano 2012;6:8052-9.

[32] Wadley ML, Hsieh IF, Cavicchi KA, Cheng SZD. Solvent Dependence of the Morphology of Spin-Coated Thin Films of Polydimethylsiloxane-Rich Polystyrene-blockPolydimethylsiloxane Copolymers. Macromolecules 2012;45:5538-45.

[33] Osuji CO. Alignment of Self-Assembled Structures in Block Copolymer Films by Solvent Vapor Permeation. Macromolecules 2010;43:3132-5.

[34] Albert JNL, Bogart TD, Lewis RL, Beers KL, Fasolka MJ, Hutchison JB, et al. Gradient Solvent Vapor Annealing of Block Copolymer Thin Films Using a Microfluidic Mixing Device. Nano Lett 2011;11:1351-7.

[35] Qiang Z, Xue J, Stein GE, Cavicchi KA, Vogt BD. Control of Ordering and Structure in Soft Templated Mesoporous Carbon Films by Use of Selective Solvent Additives. Langmuir 2013;29:8703-12.

[36] Bang J, Kim SH, Drockenmuller E, Misner MJ, Russell TP, Hawker CJ. Defect-Free Nanoporous Thin Films from ABC Triblock Copolymers. J Am Chem Soc 2006;128:7622-9.

[37] Tang C, Bang J, E. Stein G, Fredrickson GH, Hawker CJ, Kramer EJ, et al. Square Packing and Structural Arrangement of ABC Triblock Copolymer Spheres in Thin Films. Macromolecules 2008;41:4328-39.

[38] Tang C, Hur S-m, Stahl BC, Sivanandan K, Dimitriou M, Pressly E, et al. Thin Film Morphology of Block Copolymer Blends with Tunable Supramolecular Interactions for Lithographic Applications. Macromolecules 2010;43:2880-9. 
[39] Tang C, Sivanandan K, Stahl BC, Fredrickson GH, Kramer EJ, Hawker CJ. Multiple Nanoscale Templates by Orthogonal Degradation of a Supramolecular Block Copolymer Lithographic System. ACS Nano 2009;4:285-91.

[40] Hardy CG, Ren L, Ma S, Tang C. Self-assembly of well-defined ferrocene triblock copolymers and their template synthesis of ordered iron oxide nanoparticles. Chem Commun 2013;49:4373-5.

[41] Rao J, De S, Khan A. Synthesis and self-assembly of dynamic covalent block copolymers: towards a general route to pore-functionalized membranes. Chem Commun 2012;48:3427-9.

[42] Rao J, Khan A. Using reversibility of the dynamic covalent bond to create porosity in highly ordered polymer thin films under mild conditions and nano-pore functionalization in the gas phase. Polym Chem 2013;4:2691-5.

[43] Rao J, Paunescu E, Mirmohades M, Gadwal I, Khaydarov A, Hawker CJ, et al. Supramolecular mimics of phase separating covalent diblock copolymers. Polym Chem 2012;3:2050-6.

[44] Kim SH, Misner MJ, Russell TP. Solvent-Induced Ordering in Thin Film Diblock Copolymer/Homopolymer Mixtures. Adv Mater 2004;16:2119-23.

[45] Kim SH, Misner MJ, Xu T, Kimura M, Russell TP. Highly Oriented and Ordered Arrays from Block Copolymers via Solvent Evaporation. Adv Mater 2004;16:226-31.

[46] Bang J, Kim BJ, Stein GE, Russell TP, Li X, Wang J, et al. Effect of Humidity on the Ordering of PEO-Based Copolymer Thin Films. Macromolecules 2007;40:7019-25.

[47] Killops KL, Gupta N, Dimitriou MD, Lynd NA, Jung H, Tran H, et al. Nanopatterning Biomolecules by Block Copolymer Self-Assembly. ACS Macro Lett 2012;1:758-63.

[48] Mokarian-Tabari P, Collins TW, Holmes JD, Morris MA. Cyclical "Flipping" of Morphology in Block Copolymer Thin Films. ACS Nano 2011;5:4617-23.

[49] Kang M, Moon B. Synthesis of Photocleavable Poly(styrene-block-ethylene oxide) and Its Self-Assembly into Nanoporous Thin Films. Macromolecules 2008;42:455-8.

[50] Hansen CM. Hansen Solubility Parameters: A User's Handbook, 2nd Ed. Boca Raton, FL: CRC Press; 2007.

[51] Barton AFM. CRC Handbook of Solubility Parameters and Other Cohesion Parameters, 2nd Ed. Boca Raton, FL: CRC Press; 1991.

[52] Brandrup J, Immergut EH, Grulke EA, Abe A, Bloch DR. Polymer Handbook, 4th Ed. New York: John Wiley \& Sons; 1999.

[53] Dow Chemical Company. DOWANOL ${ }^{\mathrm{Tm}}$ PMA Propylene Glycol Methyl Ether Acetate. URL:

http://www.dow.com/assets/attachments/business/pcm/dowanol/dowanol_pma/tds/dowanol_pma .pdf. Accessed on November 24, 2014.

[54] Elbs H, Krausch G. Ellipsometric determination of Flory-Huggins interaction parameters in solution. Polymer 2004;45:7935-42.

[55] Ham S, Shin C, Kim E, Ryu DY, Jeong U, Russell TP, et al. Microdomain Orientation of PS-b-PMMA by Controlled Interfacial Interactions. Macromolecules 2008;41:6431-7.

[56] Hong AJ, Liu C-C, Wang Y, Kim J, Xiu F, Ji S, et al. Metal Nanodot Memory by SelfAssembled Block Copolymer Lift-Off. Nano Lett 2009;10:224-9.

[57] Ji S, Liu C-C, Liao W, Fenske AL, Craig GSW, Nealey PF. Domain Orientation and Grain Coarsening in Cylinder-Forming Poly(styrene-b-methyl methacrylate) Films. Macromolecules 2011;44:4291-300. 
[58] Wilke CR, Lee CY. Estimation of Diffusion Coefficients for Gases and Vapors. Ind Eng Chem 1955;47:1253-7.

[59] Chang J-B, Son JG, Hannon AF, Alexander-Katz A, Ross CA, Berggren KK. Aligned Sub10-nm Block Copolymer Patterns Templated by Post Arrays. ACS Nano 2012;6:2071-7.

[60] Hamley IW. Ordering in thin films of block copolymers: Fundamentals to potential applications. Prog Polym Sci 2009;34:1161-210.

[61] Kim SH, Misner MJ, Yang L, Gang O, Ocko BM, Russell TP. Salt Complexation in Block Copolymer Thin Films. Macromolecules 2006;39:8473-9.

[62] Rasappa S, Schulte L, Borah D, Morris MA, Ndoni S. Rapid, Brushless Self-assembly of a PS-b-PDMS Block Copolymer for Nanolithography. Colloid Interface Sci Commun 2014;2:1-5.

[63] Stein GE, Kramer EJ, Li X, Wang J. Layering Transitions in Thin Films of SphericalDomain Block Copolymers. Macromolecules 2007;40:2453-60.

[64] Renaud G, Lazzari R, Leroy F. Probing surface and interface morphology with Grazing Incidence Small Angle X-Ray Scattering. Surf Sci Rep 2009;64:255-380.

[65] Zhang J, Posselt D, Sepe A, Shen X, Perlich J, Smilgies D-M, et al. Structural Evolution of Perpendicular Lamellae in Diblock Copolymer Thin Films during Solvent Vapor Treatment Investigated by Grazing-Incidence Small-Angle X-Ray Scattering. Macromol Rapid Commun 2013;34:1289-95. 